Fernando Aldunate Errázuriz

\title{
La inflación $y$ sus posibles soluciones (1)
}

ENORES: Parecería, a primera vista, que fuera redun-
dante dictar una nueva conferencia sobre la inflación,
después de todo lo que se ha dicho y escrito sobre la
materia y, especialmente, después de dos importantes
y completos estudios que se han publicado en los últimos días: me
refiero al informe del Banco Central y al de don Jorge Alessandri. $\mathrm{Si}$ a esto agregamos los discursos parlamentarios y comentarios de prensa con que han sido analizados ambos trabajos, se podría pensar que ya no habría más que decir al respecto.

Sin embargo, he aceptado gustoso la invitación que me ha hecho la Universidad de Concepción, por dos razones importantes: es la primera que considero que nunca será exagerado lo que se diga o que se haga por difundir en todos los círculos nacionales la gravedad que significa para el país el ritmo alarmante que ha adquirido el proceso de inflación; y la segunda, que estimo de gran conveniencia vulgarizar y resumir las conclusiones que se desprenden de los referidos estudios que, por su extensión y tecnicismo no alcanzan muchas veces a ser debidamente apreciados en todas las esferas nacionales.

(1) Conferencia dictada en el Salón de Honor de la Universidad de Concepción, por el ex senador y actual Embajador de Chile en Argentina, señor Fernando Aldunate Errázuriz. 


\section{DEFINICION DE LA INFLACION}

Lo que es el proceso de inflación en un país ha merecido diversas definiciones por los economistas, unas más y otras menos completas. La que explica el fenómeno en forma más precisa es la que define la inflación diciendo que es la expansión del poder comprador frente a un volumen igual o inferior de las mercaderías y servicios que se pueden adquirir, entendiéndose por poder comprador el dinero en poder del público y los giros que los particulares están capacitados para hacer contra las instituciones bancarias.

Si el poder comprador y el volumen físico de la producción vendible se mantienen estacionarios o suben en la misma proporción, no hay inflación sino economía estabilizada.

En cambio, si el poder comprador se mantiene estabilizado o disminuye, y el volumen de producción de bienes se eleva en mayor proporción, se producirá una baja de precios, o sea, una deflación.

De la explicación anterior se desprende que la inflación se traduce en alzas de los precios y del costo de la vida en el interior del país, expresada esta alza en la moneda nacional, lo cual implica, naturalmente, una desvalorización monetaria y se refleja en un menor valor de la moneda nacional frente a la de otros países que no han sufrido igual fenómeno o lo han experimentado en menor intensidad.

\section{LA VERDADERA CONVENIENCIA DEL PAIS}

Para la ordenada economía de un país, para conseguir su progreso y enriquecimiento, y para mejorar el nivel de vida de sus habitantes, es absolutamente necesario que la moneda nacional se mantenga, en lo posible, estabilizada. Es indiferente que su valor sea mayor o menor con relación a las monedas de otros países: el dólar americano podría igualmente cotizarse a 500, 1,000 ó 10,000 pesos siempre que su cotización fuera estable y se mantuviera por tiempo indefinido. 
Innecesario parece señalar la conveniencia de dar a la moneda de un país la mayor estabilidad posible. La moneda estable crea la seguridad, elemento indispensable para la tranquilidad de la existencia de los habitantes de un país y para cualquier plan de desarrollo estatal o particular; permite mantener invariable el costo de la vida; empleados, obreros, comerciantes, jubilados y rentistas pueden mirar con confianza el porvenir, sin vivir permanentemente preocupados del desfinanciamiento o desequilibrio que les crea un proceso de inflación. Los sacrificios que hacen el gobierno, empleadores, empleados por crear a estos últimos una justa y equitativa previsión social son totalmente aprovechados y no se convierten en ilusiones, como ocurre en un proceso de inflación. La estabilidad monetaria hace posible el ahorro, fuente primordial de riquezas de un país; permite al gobierno y a particulares contratar créditos a largo plazo y a bajo interés para toda clase de obras públicas y empresas privadas, atrae infversionistas que proporcionan a la población mayor trabajo y oportunidades de ganancias y contribuye así al aumento de la producción nacional y al mejoramiento del nivel de vida de todos los habitantes.

Un gobierno que quiera cumplir con su primordial deber frente a sus conciudadanos que han depositado en él su confianza, no debe omitir sacrificios para mantener a cualquier precio la estabilidad monetaria.

\section{LA INFLACION EN LA HISTORIA}

Una estabilidad total de la moneda en cualquier país es un ideal difícil de alcanzar y mucho más difícil en un país nuevo y de escasa producción.

La historia monetaria de todos los países, desde los tiempos más remotos, indica que no ha habido nación alguna que haya podido librarse de la inflación y que no haya visto descender el valor de su moneda.

Algunas de estas inflaciones, producidas por guerras, catástrofes, malos gobiernos o movimientos sociales, han sido intensas y han ter- 
minado con la desvalorización total de las respectivas monedas. Como ejemplos de tales inflaciones son especialmente conocidas la del final del Imperio Romano, la de Francia con sus asignados en la época del Directorio, que siguió a la Revolución de fines del siglo XVIII, las de Alemania, Polonia, y demás países de la Europa Central, después de la primera Guerra Mundial, la de la China nacionalista durante la segunda Guerra Mundial, etc.

Otras inflaciones, que no han alcanzado el peligroso ritmo acelerado de las anteriores, han podido ser dominadas por la acción de los gobiernos; pero ellas determinaron en casi todos los países una baja más o menos lenta del valor adquisitivo de las monedas. Inglaterra, Francia, Italia, Grecia y otros países europeos sufrieron drásticas reducciones de sus monedas durante y después del segundo conflicto mundial y aun Estados Unidos se vió obligado a desvalorizar su dólar en un $40 \%$.

Chile no ha sido una excepción y, como se anota en el informe reciente del Banco Central, sufrió, entre los años 1875 y 1931, una desvalorización media del $2 \%$ anual, más acentuada en los períodos de la guerra de 1879 , de la revolución de 1891, de la caída de la conversión de 1895 y de la crisis mundial de 1931.

Del año 1932 a 1938 conoció un período de extraordinaria estabilidad durante el Ministerio de don Gustavo Ross en la segunda administración de Alessandri, para iniciar el año 1939 una inflación violenta, de un promedio algo superior al $20 \%$ anual hasta 1953; $\mathrm{y}$, desde este último año hasta hoy, la inflación ha alcanzado ya un ritmo acelerado, que ha llegado al $8 \%$ mensual, y que ha llevado a nuestra moneda a cotizarse a más de 700 pesos por dólar, cosa que hace tres o cuatro años nadie habría creído posible.

\section{LA INFLACION ES SIEMPRE PERJUDICIAL PARA UN PAIS}

Muchas personas, sostienen, sin ningún fundamento, que el régimen de inflación es conveniente a un país, porque él impulsa los negocios; y que no hay inconveniente en ir reajustando periódicamente los sueldos, salarios y precios. 
Es este el más grave de los errores en que se puede incurrir, porque si eso fuera exacto, se habría descubierto para todos los países un régimen maravilloso, que podría mejorar sus economías, sin trabajo y sin capital, utilizando exclusivamente los factores inflacionistas de aumentos de remuneraciones, colocaciones bancarias y emisiones de papel moneda. Sin embargo, basta leer la prensa, o analizar superficialmente las preocupaciones económicas de los países de mayor cultura de la tierra, para apreciar que el problema fundamental que a todos ellos interesa es el de evitar por todos los medios posibles un proceso de inflación y que sus estadistas están permanentemente atentos para contrarrestar con medidas adecuadas cualquier brote inflacionista que pueda aparecer en un momento dado.

Otra cosa es que una inflación moderada e inevitable para un país de escasa producción y balanza comercial desfavorable, pueda ser tolerada y no irrogar grandes perjuicios, como ha ocurrido en Chile en el período 1875-1930, a que nos hemos referido anteriormente. Una inflación de esa naturaleza, con especial cuidado de parte del gobierno, puede ser controlada y contrarrestada con un aumento de la producción; pero desde el momento en que ese cuidado desaparece y las personas responsables de la dirección económica de una nación ceden a presiones inflacionistas, el fenómeno empieza a tomar un ritmo acelerado y progresivo, como un rodado que se desprende de lo alto de una montaña, que arrasa y destruye cuanto encuentra a su paso. Detener el proceso en ese estado de aceleración ofrece enormes dificultades, que muchas veces resultan insuperables y sólo termina con la total desvalorización de la moneda.

\section{PERDIDA DEL AHORRO NACIONAL}

No puede ocurrir desgracia mayor para un país que ver destruída su moneda. Desaparecen con ella los sacrificios y esfuerzos de hombres laboriosos y ordenados, que pusieron su confianza en la moneda nacional y realizaron ahorros o adquirieron valores expresados en moneda corriente; se pierden las economías de viudas o me- 
nores para quienes se colocaron sus capitales en depósitos o bonos a fin de atender necesidades futuras; se destruyen los fondos de previsiones, destinados por las leyes a salvar de la miseria a inválidos o ancianos, después de una vida de trabajo.

La inflación alemana, después de la primera guerra mundial vió desaparecer miles de millones de marcos que ese pueblo laborioso había ahorrado voluntariamente o por medio de bien estudiadas leyes de previsión; y la inflación nuestra de los últimos años, que ya ha destruído un elevado porcentaje de esos fondos, amenaza arrasar con la obra de veinte años de nuestra previsión social.

Pero este no es todo el mal, porque, en una ordenada economía, esas reservas de capital, que constituyen el ahorro nacional, no sólo sirven a sus respectivos dueños o beneficiarios, sino que las aprovecha toda la colectividad y especialmente el gobierno y empresarios responsables, que en forma de empréstitos, bonos o créditos, las utilizan para obras de interés público o para el fomento de la producción.

Con un proceso de inflación acelerado, esos ahorros no se realizan, en su mayor parte, porque nadie quiere perder el fruto de su trabajo; y la nación no dispone de la mejor fuente de capitalización para entonar su economía.

\section{DESTRUCCION DE ACTIVOS INMOVILIZADOS}

Otro de los graves males que produce la inflación es la desvalorización y deficiencia de los activos inmovilizados, consistentes en establecimientos industriales y mineros, con sus respectivas maquinarias, activos que se desgastan con su uso y no pueden ser repuestos oportuna y eficientemente en un período de inflación.

Dichos activos se diferencian substancialmente de los capitales líquidos, como con toda razón lo observó el estudioso economista recientemente fallecido, don Reymond Laherrere. Aunque unos y otros activos pertenecen en dominio absoluto a particulares, estos últimos, los capitales líquidos pueden ser gastados, consumidos o sacados del país por sus dueños y su disposición o pérdida sólo intẹreșa a éstos. 
En cambio, los activos inmovilizados pertenecen, en el hecho, más a la colectividad que a sus dueños, pues difícilmente pueden ser desarraigados del lugar en que se encuentran y, en su aprovechamiento, la colectividad, en general, recibe entre un $75 \%$ al $100 \%$ de su rendimiento bruto, representado por los costos de operación, sueldos y salarios del personal, materias primas, impuestos, etc. En cambio, el dueño sólo puede disponer libremente de la utilidad líquida, después de hacer las reservas necesarias para reposiciones de maquinarias, utilidad que, según la naturaleza del negocio, puede variar entre un 0 y un $25 \%$ como máximo.

Así, pues, la mantención de los activos inmovilizados, interesa primordialmente a la colectividad y si ellos no son reparados, renovados y mejorados permanentemente, es la economía nacional la que pierde más que su dueño.

Pues bien, en un período de inflación acelerado los avalúos de los activos que figuran casi siempre en moneda corriente en los libros de las empresas, representan a cada momento un valor inferior al de reposición y, como las autoridades de Impuestos Internos sólo permiten amortizaciones de un porcentaje determinado de los avalúos de contabilidad, esas amortizaciones resultarán siempre insuficientes, tanto en su valor original, como en su valor efectivo, cuando llega el momento, después de algún tiempo, de efectuar el reemplazo. La moneda corriente acumulada para ello, mientras más acelerado sea el proceso de inflación, tendrá un menor valor adquisitivo para importar, o aún adquirir en el país, los equipos de reemplazo.

Estudios detallados, que sería largo presentar en el limitado tiempo de esta conferencia, demuestran que la mayor parte de las empresas industriales del país no han podido hacer las verdaderas reservas en moneda extranjera que corresponden a los valores de reposición de sus activos; que sus utilidades declaradas en los balances no corresponden, por la razón arriba indicada, a las utilidades reales; que la industria nacional no se ha podido colocar en situación de competir ventajosamente con las similares extranjeras; y que su rendimiento está en grave peligro de ser afectado en un futuro más o 
menos próximo. Basta con considerar la situación en que se encuentran los ferrocarriles, los puertos, los caminos, los pavimentos de la ciudad y muchas fábricas cuyas maquinarias apenas se parchan, para apreciar como la inflación está empobreciendo al país. Las nuevas generaciones de empleados y obreros que anualmente deben incorporarse al trabajo nacional no encontrarán por este motivo la ampliación de fábricas o nuevas empresas donde poder desarrollar sus actividades y todos los trabajadores del país no podrán aspirar a un mejor standard de vida porque la deficiente capitalización impedirá el aumento de la producción nacional.

En el estudio del señor Jorge Alessandri se citan casos concretos de varias empresas que no han podido durante el proceso de inflación reponer sus activos porque el gobierno controla los precios de sus productos y restringe sus amortizaciones. Las utilidades con que esas empresas figuran en sus balances, son pues, ficticias.

\section{CAPITALES EXTRANJEROS}

La falta de ahorro nacional que se produce con la inflación y que ordinariamente debería servir para capitalizar a la producción, podría ser suplida con aportes de capital extranjero, ya sea en forma de préstamos o inversiones.

Sin embargo, en un país sometido a un proceso acelerado de inflación esos aportes no se producen. Los acreedores temen, con razón, que se paralice el servicio de sus créditos en la moneda de origen, pues se requerirá cada día una mayor cantidad de moneda nacional; y el inversionista, que debe convertir su moneda extranjera a un tipo determinado de cambio, no podrá, por el proceso de inflación acelerado, retirar sus utilidades o su capital al mismo tipo; y, aunque obtenga utilidades adecuadas en moneda corriente, perderá cada día una mayor proporción de su moneda original.

Es por esa razón que, a pesar de las leyes promulgadas, de los decrețos que el gobierno ha dictado para fomentar y atraer capitales 
extranjeros, y de la propaganda que en estos momentos se hace en la prensa en los Estados Unidos, sólo vienen al país escasos capitales foráneos muy inferiores, por cierto, a los que van a otros países como Perú, Venezuela o Colombia, donde no existe proceso de inflación.

\section{DAÑO MORAL}

Tan grave como el daño económico que produce a un país la inflación, es el daño moral que la acompaña. La inflación desmoraliza la vida de un país. Nadie quiere hacer un esfuerzo, un trabajo, un negocio, porque no sabe cual será su resultado. La gente sólo piensa en gastar lo que recibe y divertirse porque sabe que su dinero valdrá cada vez menos. Se producen ganancias injustas y abusivas, no como resultado de un trabajo o un esfuerzo, sino por diferencias de precios o especulaciones. Los deudores resultan beneficiados porque pagan sus obligaciones con monedas de un menor valor, mientras que los que han querido ahorrar algún dinero pierden todo el fruto de su trabajo. Toda la vida comercial se disloca. Los comerciantes piden mayores precios por los productos que venden para cubrirse de los aumentos de valor de sus reemplazos, mientras los trabajadores extreman sus demandas de aumentos de salarios para defenderse de un alza del costo de la vida que saben va a producirse. $\mathrm{Y}$ si la autoridad interviene para regular precios, salarios y utilidades, fracasa inevitablemente y sólo crea mercados negros, escasez, sobornos e injustas discriminaciones.

No hay para una nación mayor desmoralización que la que crea la inflación, sobre todo cuando adquiere un ritmo acelerado y los reajustes no se hacen ya de año en año sino de meses, días y aun de horas, como ocurrió en la gran inflación alemana después de la primera guerra.

Una inflación de esa naturaleza termina invariablemente en revoluciones y dictaduras. 


\section{NUESTRA INFLACION A TRAVES DEL INFORME DEL BANCO CENTRAL}

El informe del Banco Central anota que el período 1935-1938 fué de absoluta estabilidad y coincide con la detención del ritmo de expansión del circulante y con un desarrollo ordenado de las finanzas públicas, que arrojan para ese lapso un superávit de $\$ 140.000,000$.

A continuación, el informe expresa que, a partir del año 1939 y hasta 1945, se inicia un primer período de inflación, que califica de predominantemente monetario y que se caracteriza por aumentos de emisiones del Banco Central, como consecuencia del incremento de redescuentos bancarios, de préstamos a instituciones semifiscales y de adquisiciones de moneda extranjera durante la guerra mundial; y por un importante desequilibrio presupuestario.

Señala, en seguida, el informe que un segundo período de inflación que denomina de expansión crediticia, se produce entre los años 1945 y 1951; y que un tercer período, de origen predominantemente fiscal, abarca los años 1952, 1953 y 1954. Por último, el informe analiza la situación económica para 1955, que califica de francamente sombría, anotando que el desequilibrio fiscal ha llegado a tal magnitud que ya no sólo el financiamiento a base de impuestos parece problemático, sino que incluso el expediente de las emisiones provocaría una expansión monetaria tan considerable, que parece dudoso que alguien quiera asumir conscientemente semejante responsabilidad.

En un anexo de su informe, el Banco destaca la proyección de los actuales índices económicos para 1960, si se continúa con el actual ritmo de inflación y presenta un cuadro, en el cual señala para ese año un presupuesto fiscal de $\$ 2.890,398$ millones; un sueldo vital mensual de 305,791 pesos y una cotización de $\$ 25,681$ para el dólar norteamericano.

Basta sólo mencionar esas cifras para comprender la grave situación que se presenta al país, que adquiere ya los caracteres de una verdadera quiebra. 


\section{REFLEXIONES SOBRE EL INFORME DEL BANCO}

Parece innecesario y de dudosa exactitud dividir en tres períodos la inflación operada desde el año 1939 hasta hoy, calificando el primero de predominantemente monetario, el segundo de predominio crediticio y el tercero de predominio fiscal.

En el fondo los tres períodos son de incremento de los medios de pago, por aumento de emisiones del Banco Central y de las colocaciones bancarias. De acuerdo con la definición de la inflación, hemos visto que ella consiste en la expansión del poder comprador frente a un volumen igual o menor de mercaderías y agregamos que se entiende por poder comprador el dinero en poder del público y los giros que los particulares están capacitados para hacer contra las instituciones bancarias.

La inflación tiene siempre, pues, un carácter monetario porque si el circulante total no aumenta y la producción no disminuye, no podrá producirse el fenómeno. Si no hay más billetes en poder del público y éste tampoco puede aumentar sus giros contra los Bancos, no podrá producirse la inflación.

Lo importante es, en cambio, estudiar por qué razones, desde el año 1939, el Banco Central se ha visto obligado a aumentar sus emisiones y sus redescuentos y los Bancos particulares a aumentar el volumen de sus colocaciones. No fué ésta una acción voluntaria y premeditada de parte de dichas instituciones que, por puro gusto, se dedicaron a expandir los medios de pago, perjudicando en esta forma a la economía del país. Si ello hubiera ocurrido, sin una causa obligada, nada sería más fácil que disminuir las emisiones y las colocaciones para terminar con la inflación.

Pero la verdad es que esas emisiones y esas colocaciones se hicieron necesarias desde 1939 porque el gobierno de ese año, y los de los sucesivos, iniciaron y mantuvieron una política de aumento de los gastos públicos y de aumentos nominales de las remuneraciones de empleados fiscales y semifiscales, de los salarios obreros y del 
sueldo vital de los empleados particulares, en una proporción mayor que el aumento de la producción nacional y mayor también que el alza de los índices de los precios al por mayor y del costo de la vida, lo que determinó para el propio gobierno y para los empresarios particulares la necesidad de disponer de una mayor cantidad de billetes y de créditos a fin de satisfacer sus gastos y sus costos.

En efecto, el informe señala que mientras el índice general de aumento de la producción subió entre 1939 y 1954 solamente de 100 a 173, o sea, no alcanzó a duplicarse, los demás índices aumentaron en la siguiente forma en el mismo período:

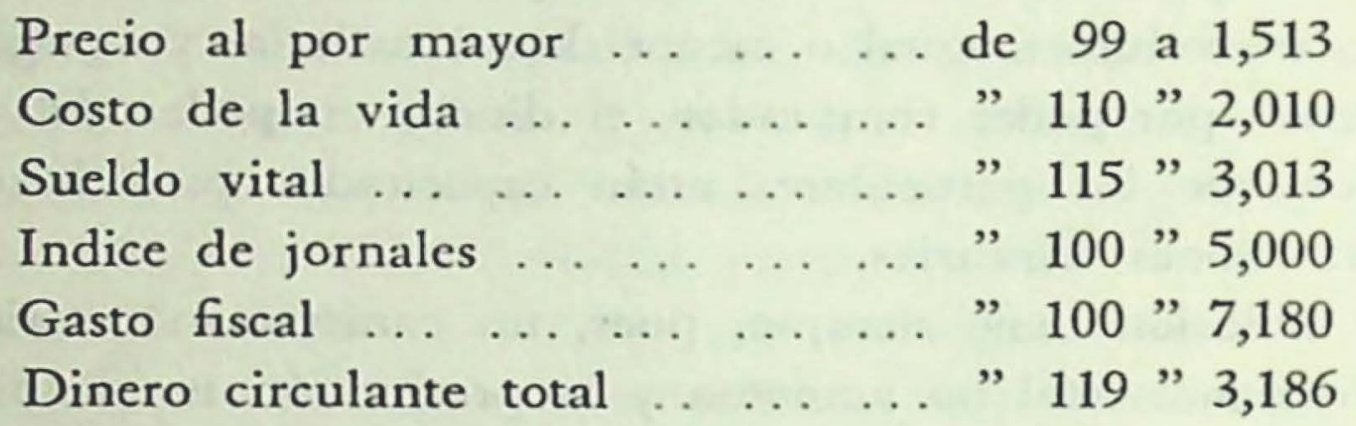

Se comprende que en estas condiciones, para hacer marchar el país, haya sido necesario aumentar las emisiones, los redescuentos y las colocaciones bancarias, o sea, el dinero circulante. Si no se hubiera procedido en esta forma, la economía del país se habría paralizado porque los empresarios, el gobierno y los particulares, en general no habrían dispuesto ni de billetes ni de cheques con fondos suficientes para pagar sus sueldos, salarios y gastos.

\section{VERDADERA CAUSA DE NUESTRA INFLACION}

La verdadera causa de nuestra inflación ha sido, pues, la política de los últimos gobiernos de fomentar por leyes, y por resoluciones administrativas, aumentos nominales de remuneraciones frente a una producción que permanecía estacionaria o aumentaba en una proporción muy inferior. 
Esa política era propiciada por gremios y sindicatos; y aquellos gobiernos, queriendo hacerse populares y conquistarse simpatías, les prestaron favorable acogida con extrema ligereza, sin considerar que ella no solucionaría ningún problema porque no iba acompañada de un aumento de la producción. El aumento del poder comprador del gremio reajustado, frente a la misma cantidad de productos, determinaba el encarecimiento de éstos, lo que afectaba a los sectores no reajustados, quienes a su vez pedían su propio reajuste, el que una vez concedido, dejaba nuevamente a los primeros en desfavorables condiciones.

$\mathrm{Y}$ así se inició lo que se ha llamado el círculo infernal de la inflación, que nos ha llevado a las deplorables condiciones actuales.

Más claramente se aprecia este resultado si nos colocamos, hipotéticamente, en dos situaciones, inverosímiles pero ilustrativas para el caso:

Supongamos, en primer lugar, que se dicte una ley que establezca que los sueldos, salarios y remuneraciones, en general, públicos y privados, deben duplicarse desde un día determinado. Esa ley sólo podría cumplirse si el Banco Central aumenta sus emisiones y los Bancos particulares sus colocaciones para permitir los pagos correspondientes. En ese mismo momento, los precios de los artículos en el mercado subirían al doble, anulando para los beneficiarios los efectos de sus reajustes y produciendo para el gobierno y para la producción los inconvenientes que ya hemos anotado.

A la inversa, poniéndonos en el caso hipotético e imposible que desde un día determinado pudiera duplicarse la producción de artículos de consumo, manteniéndose los salarios y sueldos actuales, la vida bajaría inmediatamente a la mitad, o sea, aumentaría en un $100 \%$ el standard de vida de la población.

Tan verdaderas son estas conclusiones, que dentro del aumento de precios de los productos, en general, hemos podido observar que unos suben más y otros menos según sea su abundancia o escasez; y aún, en algunos casos, se producen bajas, en un período determinado de abundancia. La carne, cuando se ha suspendido la importación 
de la Argentina por falta de divisas o interrupciones en la cordillera, ha subido en mayor proporción que otros productos, mientras los huevos, en algunos períodos de abundancia, han bajado en tal forma que el gobierno se ha visto varias veces obligado a autorizar su exportación para no provocar la liquidación de los criaderos.

\section{INUTILIDAD DE LA FIJACION DE PRECIOS}

Mientras subsistan estas condiciones, de aumento del poder comprador y escasez de productos o mercaderías, resultará siempre inútil la estabilización de los precios o medidas de orden demagógico que algunos proponen como las de "terminar con la especulación" o aplicar a los comerciantes el delito económico.

La verdad es que el precio de los bienes, productos y servicios en una unidad económica como la que constituye un país determinado, no depende de lo que uno o varios vendedores o comerciantes quieran pedir por ellos, sino de su abundancia o escasez y de los medios de pago de que el público puede disponer para adquirirlos. Si esto no fuera así, nunca habría podido producirse la pérdida o la quiebra de un comerciante porque, en caso de dificultades económicas, le habría bastado subir los artículos de su comercio en todo lo que fuere necesario para salir de apuros. Sin embargo, sabemos que esto no siempre se puede hacer y que son infinitos los casos de comerciantes que han caído en quiebra o insolvencia.

Por esta razón han estado siempre condenadas a un fracaso las leyes y medidas creando organismos con diversos nombres, como Comisariato de Subsistencias y Precios o Superintendencia de Abastecimientos, destinados a fijar y controlar los precios de los artículos de consumo. Aún cuando dichos organismos han actuado bajo gobiernos y autoridades que se dicen defensoras de las clases populares y con personal que suponemos inspirado en los mejores propósitos de mantener bajos los precios, ellos no han podido hacer otra cosa que constatar el alza de los costos y autorizar los aumentos de precios para impedir que la producción de los artículos controlados dismi- 
nuya o desaparezca. Proceder en otra forma habría sido lo mismo que impedir, por la fuerza, que estalle una caldera herméticamente cerrada mientras se aumenta el fuego que la alimenta.

\section{LA EXPERIENCIA DE OTROS PAISES}

Este problema, que no es solamente nuestro, se ha presentado en otros países de alta cultura como Inglaterra, y son los propios trabajadores los que han propuesto las verdaderas soluciones.

Los cables del día 8 de septiembre último, nos relatan los acuerdos de los llamados Congresos de Uniones Gremiales, que se reúnen en Inglaterra anualmente para resolver sus problemas y necesidades y a cuyas deliberaciones concurrieron el año último, sindicatos que representaban a más de 8 millones de trabajadores.

Pues bien, esos sindicatos, frente a un incremento del costo de la vida producido últimamente en ese país, no acordaron nuevos pliegos de peticiones, ni huelgas ni otras demandas de orden económico.

Por el contrario, el cable nos dice que los acuerdos fueron los siguientes: a) sanciones para quienes se declaren en huelga ilegal por considerar que ellas perturban el proceso económico y desprestigian el movimiento sindical; b) rechazo de la pretensión de disminuir la jornada de trabajo a 40 horas por estimar que el imperativo del momento es producir más para poder disfrutar de las ventajas que tienen obreros de otros países (Estados Unidos); c) repudio, por inmensa mayoría de votos, de la idea de traspasar al Estado actividades que se desenvuelven actualmente bajo el control de la iniciativa privada.

En esta forma, los sindicatos de trabajadores británicos confirman la posición que hemos expuesto y consideran que los países son unidades políticas, sociales y económicas en que el interés de cada habitante está subordinado al de los demás, y en que el éxito, la prosperidad y la riqueza de unos representa no sólo el auge de ellos, sino la conveniencia del resto de la comunidad. 


\section{LA SOLUCION}

De lo anteriormente expuesto, la solución fluye lógicamente; para terminar con la inflación y mejorar el nivel de vida de los habitantes de un país no existe otra fórmula que aumentar la producción de bienes y artículos de consumo. Mientras más alta es 1 prociucción de un país, mejor es el standard de vida de la población y su moneda es más estable y más sana.

Estados Unidos nos da un ejemplo. Su alta mecanización y capitalización le permite alcanzar una producción superior a 2,000 dólares por habitante, mientras la producción de Chile apenas llega a 200 dólares por habitante. Así se explican los altos salarios de los obreros americanos, su elevado standard de vida y la solidez de su moneda.

\section{¿COMO AUMENTAR LA PRODUCCION?}

Ahora bien, ¿cuáles son los medios para que un país aumente su producción?

La materia es amplia y sale ya de los límites de esta conferencia y del tiempo reservado para ella.

Sin embargo, no está de más que, a título de simple exposición, indiquemos las condiciones que a nuestro juicio deben prevalecer en un país para que su producción aumente. Esas condiciones, que pueden ser abonadas con macizos argumentos, representan además los resultados que varios países, sometidos a distintos regímenes de gobierno y aplicando diversos sistemas económicos, han obtenido en su búsqueda de mayor producción. Ellos son:

1. Fomento de la libre empresa, base del poderío norteamericano y de la fantástica recuperación de la Alemania Occidental.

2. Libertad de cambios, que estimula, como ha ocurrido en el Perú, el aporte de capitales extranjeros para la creación de nuevas fuentes de producción. 
3. Estabilidad monetaria, que permite la formación de ahorros nacionales, destinados a capitalizar la producción.

4..$^{\circ}$ Impuestos moderados, que no sean superiores a los que rigen en otros países poco desarrollados que compiten entre sí por atraer nuevos capitales a su economía.

Un país que ofrezca las anteriores condiciones puede tener la seguridad de que estimulará al máximo su producción, porque en estos momentos existen capitales importantes de los países europeos y americanos que buscan colocaciones en naciones nuevas, alejadas de posibles campos de conflictos bélicos, y donde puedan encontrar interés más elevado y seguridad para sus inversiones.

\section{DIFICULTADES DE NUESTRA INFLACION}

No desconocemos las dificultades que una solución semejante presenta para su aplicación en Chile.

Los déficit presupuestarios acumulados, el déficit de divisas y las persistentes demandas por aumentos de sueldos y salarios de empleados públicos, empleados particulares y obreros en general, agravan el problema cada día más y dan a nuestra inflación un ritmo tan acelerado, que el llamado círculo infernal en que vivimos desde hace 17 años, parece difícil de detener; y el gobierno recurre, en su desesperación, a procedimientos precisamente contrarios de los que indicamos para aumentar la producción, como son los aumentos de impuestos, y mayor intervención en los cambios internacionales y en el desarrollo de la empresa privada.

Sin embargo, el problema no es insoluble, especialmente por la favorable circunstancia que hoy se presenta de la escasez mundial de cobre y del alto precio de ese producto.

Esta circunstancia permitiría al gobierno obtener entradas extraordinarias de consideración, en moneda extranjera, por lo menos en este y en el próximo año, de las tres empresas norteamericanas productoras de cobre actualmente establecidas en Chile, siempre que ellas pudieran trabajar sin interrupciones ni huelgas y sin demandas exage- 
radas de remuneraciones de su personal de empleados y obreros, en vista de que el Fisco, con el nuevo trato tributario a esas empresas, recibe el $75 \%$ de sus utilidades líquidas y es, en el hecho, su más fuerte accionista.

Si al mismo tiempo se instaura una verdadera política de sobricdad y economía en los gastos fiscales, postergando transitoriamente algunas obras y suprimiendo desembolsos de otro orden, sería posible romper, en el presupuesto fiscal, el círculo infernal de la inflación, de que ya hemos hablado e instaurar con prudencia una política deflacionista moderada que permita, primero, disminuir el ritmo de desvalorización de nuestra moneda y llegar más adelante a su estabilidad.

El índice del costo de la vida tendería, en esta forma, a normalizarse; los reajustes de remuneraciones se harían al comienzo de menor consideración y después innecesarios; empezarían a formarse ahorros nacionales; y el factor confianza así cimentado, atraería muchos capitales para incrementar la producción.

Esta labor, difícil y no exenta de complicaciones, debería ser la obra de hombres técnicos, de gran capacidad, experiencia y honorabilidad, en la cual todos los chilenos estaríamos obligados a colaborar, poniendo cada cual algo de su parte. Gobierno, partidos políticos, empresarios, empleados y obreros deben comprender que si esta oportunidad se pierde, a todos nos esperan grandes sufrimientos y nuestra democracia verá días muy sombríos”. 